BNL-112655-2016-JA

\title{
Staging Life in an Early Warm 'Seltzer' Ocean
}

\author{
Martin Schoonen, RIS4E, and Alexander Smirnov
}

Submitted to the Journal "Elements"

October 2016

\section{Environment, Biology, Nuclear Science, and Nonproliferation Directorate \\ Brookhaven National Laboratory}

\author{
U.S. Department of Energy, \\ Office of Science (SC), \\ Biological and Environmental Research (BER) (SC-23)
}

Notice: This manuscript has been authored by employees of Brookhaven Science Associates, LLC under Contract No. DE- SC0012704 with the U.S. Department of Energy. The publisher by accepting the manuscript for publication acknowledges that the United States Government retains a non-exclusive, paid-up, irrevocable, world-wide license to publish or reproduce the published form of this manuscript, or allow others to do so, for United States Government purposes. 


\section{DISCLAIMER}

This report was prepared as an account of work sponsored by an agency of the United States Government. Neither the United States Government nor any agency thereof, nor any of their employees, nor any of their contractors, subcontractors, or their employees, makes any warranty, express or implied, or assumes any legal liability or responsibility for the accuracy, completeness, or any third party's use or the results of such use of any information, apparatus, product, or process disclosed, or represents that its use would not infringe privately owned rights. Reference herein to any specific commercial product, process, or service by trade name, trademark, manufacturer, or otherwise, does not necessarily constitute or imply its endorsement, recommendation, or favoring by the United States Government or any agency thereof or its contractors or subcontractors. The views and opinions of authors expressed herein do not necessarily state or reflect those of the United States Government or any agency thereof. 


\section{Staging Life in an Early Warm 'Seltzer' Ocean}

Martin Schoonen, Brookhaven National Laboratory, Upton, NY 11793-5000, USA; and RIS ${ }^{4}$ E, Department of Geosciences, Stony Brook, NY 11764-2100, USA.

Alexander Smirnov, USA.

\section{Abstract}

A period as short as 20 million years within the first 100 million years after the formation of the Moon may have set the stage for the origin of life. The atmosphere contained more carbon dioxide than any other period afterwards. The carbon dioxide sustained greenhouse conditions, accelerated the weathering of a primitive crust and may have led to conditions conducive to the formation of the building blocks of life. The conversion of $\mathrm{CO}_{2}$ as well as $\mathrm{N}_{2}$ may have been facilitated by clays, zeolites, sulfides and metal alloys formed as the crust reacted with a warm 'seltzer' ocean. Geochemical modeling is used to constrain the conditions favorable for the formation of these potential mineral catalysts.

\section{Introduction}

One of the most challenging geological problems to constrain is the composition of the atmosphere, ocean, and solid Earth during the period preceding the origin of life. This period of time did not leave a rock record and we are left to infer the conditions on the prebiotic Earth by applying what we can glean from comparative planetary science, zircons that formed as far back as $4.4 \mathrm{Ga}$, and theoretical approaches. Constraining the conditions during the first billion years after accretion has attracted considerable attention because it sets the conditions for the origin of life and it may provide the proverbial building blocks of life through abiotic reactions. Within this context there has been interest in evaluating possible mineral-assisted or mineral-catalyzed pathways to make amino acids, form and polymerize nucleotides, as well as form other relevant organic compounds as an alternative to delivery by meteorites and asteroids (Schoonen et al. 2004; Cleaves et al. 2012; Pizzarello and Shock 2016). Formed during weathering, clays may have provided a mechanism to concentrate and protect biomolecules via intra-layer sorption (Lyon et al. 2010). It is important to note that mineral-based reactions may also decompose building blocks of life-a consideration that has attracted far less attention than their formation (Schoonen et al. 2004).

Any Earth-bound pathway involving minerals forming, transforming, concentrating, stabilizing, protecting or decomposing possible building blocks of life requires one to evaluate what type of minerals could have been present and what range of conditions might have governed the reactions of interest. There may have been a range of environments (e.g., various types of submarine hydrothermal vents, surficial rock exposures, and/or hot springs) during this early period, referred to as the Hadean. The problem seems intractable at first blush and the parameter space too broad to develop meaningful constraints. However, the analyses of zircons formed during the Hadean, advanced models of the atmosphere during the first billion years after the formation of 
Earth, and experimental work provide useful new insights that allow for much tighter constraints than decades ago when some of the most notable scenarios for the origin of life were first proposed without the benefit of any geochemical or mineralogical constraints. The purpose of this essay is to provide an assessment of the factors that determine the composition of secondary mineral assemblages and associated fluids as well as an assessment of the environments most likely to lead to formation of reduced carbon and nitrogen compounds that may have primed early Earth for the emergence of life.

\section{Conditions on the Early Earth}

After the Moon-forming event, occurring 50 to 150 Myr after the Earth began to concrete, the planet was too hot for about 2 million years for liquid water to be stable. Once sufficiently cooled, Earth settled into a period of perhaps as long as 20 to 100 Myr in which liquid water was present along with a $\mathrm{CO}_{2}$-dominated atmosphere (Zahnle 2006). The partial pressure of $\mathrm{CO}_{2}$ in the atmosphere started perhaps as high as 100 bars and then decreased to levels below 1 bar (Sleep et al. 2001; Zahnle 2006). The rate at which $\mathrm{CO}_{2}$ was lost is governed by the kinetics of the reaction of dissolved $\mathrm{CO}_{2}$ with rocks.

Elevated $\mathrm{CO}_{2}$ during this period may have created favorable conditions for the origin of life. $\mathrm{CO}_{2}$ is a greenhouse gas and would have contributed to elevated ocean temperatures, perhaps exceeding $100^{\circ} \mathrm{C}$ with elevated atmospheric pressure suppressing boiling. These water-rock reactions would have consumed $\mathrm{CO}_{2}$, cooling Earth and possibly turning it from a hot planet into an ice-covered one. Removing most of the $\mathrm{CO}_{2}$ out of the atmosphere may have taken around 100 Myr. During the last 20 Myr of this transition, with 5 to 25 bar of $\mathrm{CO}_{2}$ left, the temperature of the ocean would have been between 60 and $110^{\circ} \mathrm{C}$ (Sleep et al. 2001; Zahnle 2006). In essence, the ocean was a warm seltzer water that reacted with the crust and lost its fizz over time. It is during this transition that the composition of the earliest oceans, fluids entrained in the crust, and secondary mineral assemblages are shaped. In addition, field studies and experimental work show that as part of the interaction of $\mathrm{CO}_{2}$-containing water with crustal materials, a range of organic compounds form via abiotic reactions (McCollum 2013). Hence, given the high concentrations of dissolved $\mathrm{CO}_{2}$ in oceans, this relatively short period of time may have produced a significant amount of organic compounds that set the stage for the origin of life.

Apart from the presence of elevated $\mathrm{CO}_{2}$ in the atmosphere, a major control on the outcome of any water-rock process is the chemical and mineralogical composition of the rocks involved. Without a Hadean rock record we are left to infer what type or rocks might have made up the Earth's primitive crust. The only relicts of the Hadean are zircons that were formed 3.5 to $4.4 \mathrm{Ga}$ ago (Valley 2006). Zircons are common primary accessory minerals in granitoid rocks and withstand physical and chemical weathering, allowing them to be deposited and redeposited for billions of years. In essence, zircons are small windows into Hadean conditions. Those found in the Jack Hills, Western Australia, suggest that liquid water may have been present on Earth as early as $4.2 \mathrm{Ga}$ ago. While the zircons are invaluable in helping to constrain Hadean conditions, they are likely derived from small vestiges of rocks formed by partial melting of a Hadean crust that was largely ultramafic to mafic in composition (Taylor and McLennan 2009). Ultramafic and mafic igneous rocks are 
characterized by their high content of magnesium and iron-rich minerals and relatively low silica content (ultramafic rocks contain less silica than mafic rocks).

On the basis of a higher heat flow during the Hadean, it is a popular notion that most of the earliest crust was komatiitic in composition, an igneous rock high in $\mathrm{Mg}$ content and dominated by olivine (Nisbet and Sleep 2001; Meunier et al. 2010). Others have argued that a composition similar to Mid-Oceanic Ridge Basalts (MORB) or tholeiitic basalts is most likely for the Hadean crust (Taylor and McLennan 2009). Peridotite, a mantle material found in modern settings, such as the Lost City off-axis submarine hydrothermal system, may have also been exposed during the Hadean. Rather than settling on one particular rock type, it is prudent to consider all three ultramafic to mafic compositions as well as a composition that accounts for the small vestiges of continent crust that must have been present to account for the Hadean zircons. The most realistic rock type to represent early vestiges of the continental crust is of tonalitic composition, with major Na-rich plagioclase and minor quartz and orthoclase (Nutman 2006).

Having settled on a range of rocks and assuming that there was liquid water from 4.2 Ga onward, the next step is to consider the setting of the water-rock interaction. Principally, we need to decide whether the water-rock interaction proceeds while allowing for rapid exchange with the atmosphere or restricted from the atmosphere. Surficial or shallow environments are expected to retain equilibrium between the fluid and the atmosphere throughout the water-rock interaction. By contrast, in deep environments or rock-dominated environments (e.g. fluids in cracks, Figure 1), the water infiltrating into the rock is in equilibrium with the atmosphere; however, upon deeper infiltration, the fluid evolves out of equilibrium with the atmosphere. In a modern analog, the difference is analogous to modeling reactions in a littoral zone versus reactions in a deep aquifer. Figure 1 provides a schematic representation of the settings explored and the variables to be explored. The purpose of geochemical calculations is to illustrate under what set of conditions secondary minerals seen as promising materials to act as catalysts, such as clays, zeolites and sulfides, may form. The calculations also constrain the composition of the resulting fluids (Schoonen et al. 2004; Cleaves et al. 2012). In addition to clays;
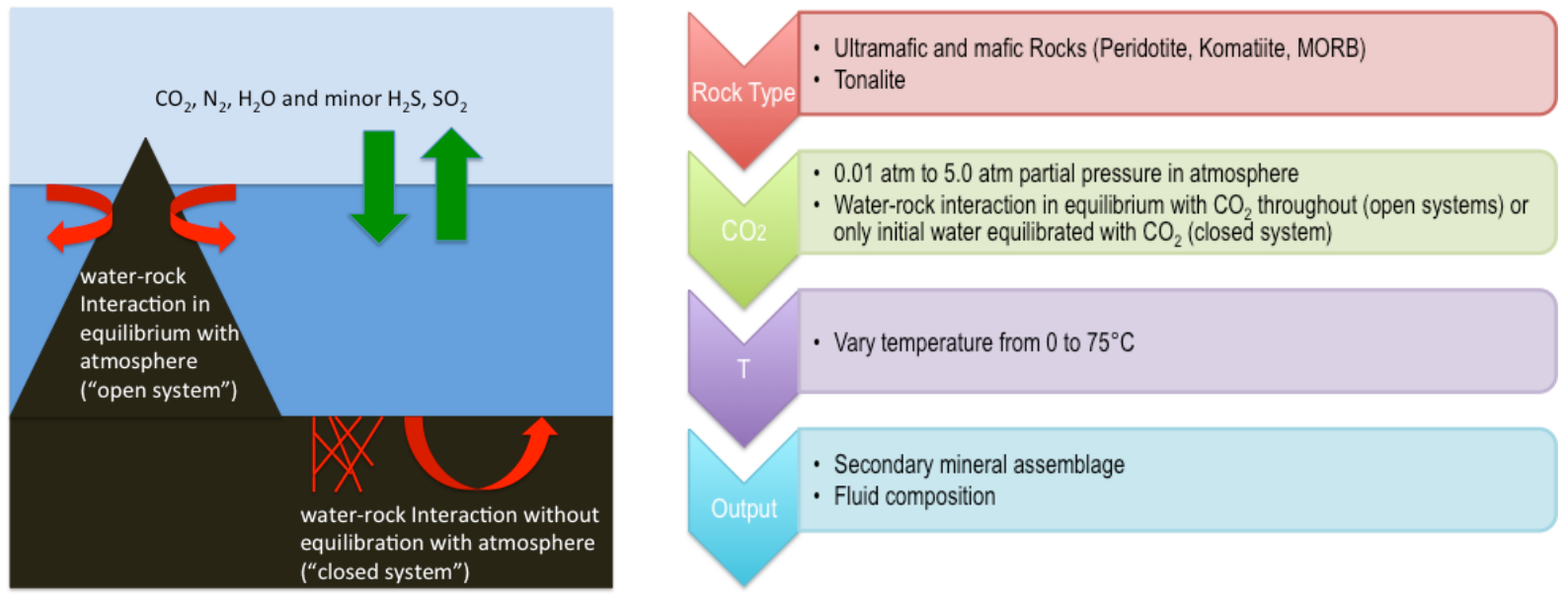

Figure 1. Schematic figure of settings (left) and variables (right) to be evaluated.

zeolites; and sulfides there is an emerging body of literature that shows that metallic alloys form as part of the alteration of ultramafic and mafic rocks (Filippidis 1985; Smirnov et al. 
2008). Although small in abundance, metallic alloys might have played a critical role in the conversion of $\mathrm{CO}_{2}$ and $\mathrm{N}_{2}$ on the early Earth into reactive compounds important to the formation of the building blocks of life.

\section{Modeling Water-Rock Interaction}

Building on the decades-long efforts led by various geochemists, notably Helgeson at UC-Berkeley, Reed at the University of Oregon, Wolery at Lawrence Livermore National Laboratory, Shock at Washington University and Arizona State University, and Bethke at University of Illinois, it is possible to efficiently conduct computer-based water-rock simulations (Bethke 2008). We stress that it is important to conduct an ensemble of simulations so that a range of conditions, such as different rock, gas and solution compositions, can be explored. This is particularly important here as the problem at hand is poorly constrained. For this essay, we expand on earlier work in which we explored the interaction of komatiite and tonalite with water in a $\mathrm{CO}_{2}$-rich atmosphere (Schoonen et al. 2004) using Geochemist's Workbench (Bethke 2008). The emphasis in these water-rock interaction simulations is on the weathering of major rock-forming minerals. The weathering process governs the composition of the water it reacts with and dictates the suite of secondary minerals formed. It should be kept in mind, however, that these calculations do not take into account any kinetic effects that may lead to non-equilibrium assemblages. This is commonly addressed in thermodynamic calculations by suppressing the formation of minerals that are known not to form during weathering processes. An example might be the formation of quartz. Although predicted to form on the basis of its thermodynamic stability, other forms of silica, such as chalcedony, are often formed as basaltic rocks weather.

For the purpose of this essay we have summarized the results of several representative simulations in the form of heat maps used in the Biological Sciences to visualize multi-dimensional data. Figure 2 summarizes the results of simulations with four rock types at constant $\mathrm{P}_{\mathrm{CO}_{2}}(5 \mathrm{~atm})$ and $\mathrm{T}\left(75^{\circ} \mathrm{C}\right)$. For each simulation the secondary mineral composition after 50 gram of rock reacted with a liter of water was converted to relative abundances in terms of weight percentage of major classes of secondary minerals. In addition, the molar ratio of $\mathrm{Ca}+\mathrm{Mg}$ over $\mathrm{Na}+\mathrm{K}$ (recast as a logarithm) and $\mathrm{pH}$ are shown. In Figure 3, the influence of $\mathrm{P}_{\mathrm{CO}_{2}}$ on reactions with one rock type, MORB, is explored, while in Figure 4 the temperature dependence on reactions with MORB is explored at a constant $\mathrm{P}_{\mathrm{CO}_{2}}(2 \mathrm{~atm})$.

It is important to note that in the simulations presented here the reduction of $\mathrm{CO}_{2}$ to methane and other reduced forms of carbon is blocked. This is a reasonable first order approximation as these reactions do not go forward without a catalyst and are slow in the presence of a suitable catalyst at the temperatures considered here. Even if the atmosphere contained substantial amounts of molecular hydrogen-perhaps episodically as the result of impacts (Zahnle et al. 2010) - $\mathrm{CO}_{2}$ is unlikely to be reduced by hydrogen in open systems without a suitable catalyst and higher temperatures. In closed ultramafic or mafic systems, some $\mathrm{CO}_{2}$ reduction to methane is likely as will be explained below, but some methane formation will not materially change the secondary mineral assembly. Hence, as a first approximation we consider $\mathrm{CO}_{2}$ to be inert, even in closed systems. 


\begin{tabular}{|c|c|c|c|c|c|c|c|c|c|c|}
\hline \multirow[b]{2}{*}{ Conditions } & \multirow[b]{2}{*}{ Rock Type } & \multicolumn{7}{|c|}{ SECONDARY MINERAL ASSEMBLAGE (wt \%) } & \multicolumn{2}{|c|}{ FLUID } \\
\hline & & Silica & Clay & Zeolite & Carbonate & $\mathrm{AlOOH}$ & Sulfide & Other & $\begin{array}{c}\log (\mathrm{Ca}+\mathrm{Mg}) \\
/(\mathrm{Na}+\mathrm{K})\end{array}$ & $\mathrm{pH}$ \\
\hline & MORB & 39.49 & 0.00 & 0.00 & 35.20 & 14.81 & 9.58 & 0.92 & -1.47 & 5.97 \\
\hline \multirow{3}{*}{ 림 } & Komatiite & 32.80 & 0.00 & 0.00 & 58.59 & 5.78 & 2.82 & 0.00 & -0.26 & 5.62 \\
\hline & Peridotite & 29.32 & 0.00 & 0.00 & 61.76 & 1.58 & 7.26 & 0.09 & 0.17 & 5.55 \\
\hline & Tonalite & 54.41 & 0.00 & 0.00 & 19.61 & 19.59 & 6.37 & 0.01 & -2.06 & 6.19 \\
\hline \multirow{4}{*}{ نُ } & MORB & 0.00 & 41.48 & 46.54 & 10.76 & 0.00 & 0.03 & 1.19 & -0.82 & 7.46 \\
\hline & Komatiite & 0.00 & 89.10 & 0.00 & 10.79 & 0.00 & 0.02 & 0.09 & -2.85 & 9.25 \\
\hline & Peridotite & 0.00 & 88.92 & 0.00 & 9.68 & 0.00 & 0.02 & 1.38 & -2.69 & 9.37 \\
\hline & Tonalite & 4.91 & 38.93 & 49.52 & 6.61 & 0.00 & 0.03 & 0.00 & -2.84 & 7.31 \\
\hline
\end{tabular}

Figure 2. Summary of illustrative geochemical model calculations exploring the influence of rock type on the composition of secondary assemblage and fluid composition. Calculations assuming 5 atm $\mathrm{CO}_{2}$ in atmosphere and temperature of $75^{\circ} \mathrm{C}$. See text and Fig. 1 for details on 'open' and 'closed' conditions.

\begin{tabular}{|c|c|c|c|c|c|c|c|c|c|c|}
\hline \multirow[b]{2}{*}{ Conditions } & \multirow[b]{2}{*}{$\mathbf{P}_{\mathrm{CO} 2}(\mathrm{~atm})$} & \multicolumn{6}{|c|}{ SECONDARY MINERAL ASSEMBLAGE (wt \%) } & \multicolumn{3}{|c|}{ FLUID } \\
\hline & & Silica & Clay & Zeolite & Carbonate & $\mathrm{AlOOH}$ & Sulfide & Other & $\begin{array}{c}\log (\mathrm{Ca}+\mathrm{Mg}) \\
/(\mathrm{Na}+\mathrm{K})\end{array}$ & $\mathrm{pH}$ \\
\hline \multirow{5}{*}{$\begin{array}{l}\text { Z } \\
\text { ù }\end{array}$} & 5.00 & 39.49 & 0.00 & 0.00 & 35.20 & 14.81 & 9.58 & 0.92 & -1.47 & 5.97 \\
\hline & 2.00 & 5.34 & 53.22 & 0.00 & 30.16 & 0.51 & 9.83 & 0.94 & -2.15 & 6.35 \\
\hline & 1.00 & 5.08 & 53.66 & 0.00 & 30.15 & 0.34 & 9.83 & 0.94 & -2.53 & 6.65 \\
\hline & 0.10 & 0.00 & 26.88 & 45.72 & 16.58 & 0.00 & 9.76 & 1.06 & -2.23 & 7.17 \\
\hline & 0.01 & 0.00 & 22.06 & 54.94 & 12.02 & 0.00 & 9.86 & 1.11 & -0.99 & 7.42 \\
\hline \multirow{5}{*}{ 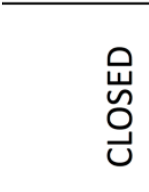 } & 5.00 & 0.00 & 41.48 & 46.54 & 10.76 & 0.00 & 0.03 & 1.19 & -0.82 & 7.46 \\
\hline & 2.00 & 0.00 & 56.53 & 29.53 & 4.64 & 8.06 & 0.00 & 1.24 & -3.09 & 10.51 \\
\hline & 1.00 & 0.00 & 51.70 & 44.60 & 2.42 & 0.00 & 0.02 & 1.25 & -2.08 & 10.17 \\
\hline & 0.10 & 0.00 & 53.90 & 44.60 & 0.22 & 0.00 & 0.02 & 1.26 & -2.24 & 10.27 \\
\hline & 0.01 & 0.00 & 54.01 & 44.71 & 0.00 & 0.00 & 0.02 & 1.26 & -2.33 & 10.33 \\
\hline
\end{tabular}

Figure 3. Exploring the influence of the atmospheric $\mathrm{CO}_{2}$ pressure on the composition of the secondary mineral assemblage and the fluid composition. All calculations assume MORB as rock type and a temperature of $75^{\circ}$ C. See text and Fig. 1 for details on 'open' and 'closed' conditions.

\begin{tabular}{|c|c|c|c|c|c|c|c|c|c|c|}
\hline \multirow[b]{2}{*}{ Conditions } & \multirow[b]{2}{*}{$\mathrm{T}\left({ }^{\circ} \mathrm{C}\right)$} & \multicolumn{6}{|c|}{ SECONDARY MINERAL ASSEMBLAGE (wt \%) } & \multicolumn{3}{|c|}{ FLUID } \\
\hline & & Silica & Clay & Zeolite & Carbonate & $\mathrm{AlOOH}$ & Sulfide & Other & $\begin{array}{c}\log (\mathrm{Ca}+\mathrm{Mg}) \\
/(\mathrm{Na}+\mathrm{K})\end{array}$ & $\mathrm{pH}$ \\
\hline \multirow{5}{*}{$\begin{array}{l}\text { Zu } \\
\text { o } \\
\text { o }\end{array}$} & 75 & 5.34 & 53.22 & 0.00 & 30.16 & 0.51 & 9.83 & 0.94 & -1.47 & 5.97 \\
\hline & 50 & 39.58 & 0.00 & 0.00 & 35.09 & 14.82 & 9.59 & 0.92 & -2.15 & 6.35 \\
\hline & 25 & 24.44 & 31.50 & 0.00 & 33.68 & 0.00 & 9.48 & 0.91 & -2.53 & 6.65 \\
\hline & 10 & 26.01 & 28.08 & 0.00 & 35.53 & 0.00 & 9.47 & 0.91 & -2.23 & 7.17 \\
\hline & 0 & 27.23 & 26.08 & 0.00 & 35.49 & 0.00 & 9.54 & 0.91 & -0.99 & 7.42 \\
\hline \multirow{5}{*}{ 를 } & 75 & 0.00 & 56.53 & 29.53 & 4.64 & 8.06 & 0.00 & 1.24 & -0.82 & 7.46 \\
\hline & 50 & 0.00 & 44.63 & 47.19 & 6.92 & 0.00 & 0.04 & 1.22 & -3.09 & 10.51 \\
\hline & 25 & 0.00 & 41.04 & 46.58 & 11.14 & 0.00 & 0.06 & 1.18 & -2.08 & 10.17 \\
\hline & 10 & 0.00 & 32.10 & 48.56 & 16.60 & 1.61 & 0.09 & 1.03 & -2.24 & 10.27 \\
\hline & 0 & 0.00 & 49.79 & 25.70 & 23.41 & 0.00 & 0.12 & 0.97 & -2.33 & 10.33 \\
\hline
\end{tabular}

Figure 4. Exploring the influence of temperature on the composition of the secondary mineral composition and the fluid composition. All calculations assume MORB as rock type and a pressure of $2 \mathrm{ATM} \mathrm{CO}_{2}$ in the atmosphere. See text and Fig. 1 for details on 'open' and 'closed' conditions. 
The results of the calculations in which the water-rock interaction takes place at $75^{\circ} \mathrm{C}$ while maintaining equilibrium with $\mathrm{CO}_{2}$ at 5 atm-here designated as "open" systems - show that none of the secondary mineral assemblages contain zeolites or clays. The secondary mineral assemblages are instead dominated by a combination of $\mathrm{SiO}_{2}$ and carbonates. The formation of carbonates effectively locks up most of the divalent cations; only iron is present as a metal sulfide. These modeling results are consistent with experimental work on water-basalt interaction at $10 \mathrm{~atm} \mathrm{CO}_{2}$ (Gysi and Stefánsson 2012). The secondary mineral assemblage for all starting materials changes considerably if the initial water is equilibrated with $\mathrm{CO}_{2}$ but the equilibrium with $\mathrm{CO}_{2}$ is not maintained as the rock reacts. These "closed" conditions lead to secondary mineral assemblages that have far less carbonates, are essentially devoid of $\mathrm{SiO}_{2}$ and sulfides, and contain abundant clays and/or zeolites. The composition of the resulting fluid also changes depending on whether the system maintains equilibrium with the atmosphere or not. Equilibrium with $\mathrm{CO}_{2}$ throughout the water-rock interaction buffers the $\mathrm{pH}$ to values slightly below neutral, while in closed systems the resulting solution is alkaline. Fluids in closed systems tend to be strongly enriched in monovalent cations compared to divalent cations when compared to open systems. In fact, the open system simulation with peridotite suggests that the fluid would be enriched in divalent ions compared to monovalent ions. Solutions dominated by divalent ions may have destabilized primitive membrane vesicles (Monnard et al. 2002) and impeded a critical step toward cellular life (Deamer et al. 2002).

Besides the composition of the crust, the level of $\mathrm{CO}_{2}$ concentration in the atmosphere is an important factor in determining the composition of the secondary mineral assemblage. As $\mathrm{CO}_{2}$ falls from 5 to $0.1 \mathrm{~atm}$ in open systems (Fig 3), the secondary mineral assemblage starts to contain zeolite at the expense of $\mathrm{SiO}_{2}$ and clays, while the amount of carbonates is also reduced. In closed systems, the change in $\mathrm{CO}_{2}$ is not as consequential.

A decrease in temperature from $75^{\circ} \mathrm{C}$ down to $0^{\circ} \mathrm{C}$ induces some modest changes in the secondary mineral assemblage. The amount of carbonate in closed systems increases with a decrease in temperature. Perhaps the most important change is the switch from fluids dominated by $\mathrm{Na}+\mathrm{K}$ to fluids dominated by $\mathrm{Ca}+\mathrm{Mg}$ as temperature decreases in open systems (Fig. 4). Given that waters dominated by divalent cations destabilize membrane vesicles (Monnard et al. 2002), the warm conditions during this early stage of Earth history would have been more favorable for the assembly of membrane vesicles.

The major implication illustrated by Figures 2 through 4 is that water-rock interaction during the warm seltzer stage of the Early Earth would have produced a range of fluids with contrasting composition. The ocean waters would have been slightly acidic as a result of the high carbon dioxide content of the atmosphere, while fluids that infiltrated into ultramafic or mafic rocks would have been alkaline apart from some compositional differences. Mixing of these types of fluids would have set up steep chemical gradients and chemical disequilibrium. Russell and co-workers (Russell et al. 2010) have argued that life arose in these mixing zones as a result of the contrasting chemical composition and the resulting chemical disequilibrium. 


\section{Formation of Metallic Catalysts}

The modeling approach illustrated above allows one to constrain the overall fluid conditions and major secondary mineral assembly as a rock weathers; however, this approach does not address the fate of minor and trace elements incorporated in rockforming minerals. Some of these minor and trace elements, such as transition metals, may have played a key role in setting the stage for life. A case in point is the fate of nickel incorporated in olivine, a major mineral component in ultramafic to mafic rocks (e.g., peridotites and basalts). These rocks contain often up to $0.5 \mathrm{wt}$. \% $\mathrm{NiO}$ substituted in the structures of olivines and other rock forming minerals. The forsterite-fayaliteliebenbergite solid solution, commonly referred to as olivine- $\left(\mathrm{Mg}, \mathrm{Fe}, \mathrm{Ni}^{2} \mathrm{Si}_{2} \mathrm{O}_{4}\right.$-is particularly reactive because the $\mathrm{SiO}_{4}$ tetrahedra in its structure are not polymerized.

Molecular hydrogen and heat are generated along with metallic secondary minerals as olivine reacts with water, a process referred to as serpentinization (Figure 5). The molecular hydrogen formation is driven by a reaction between metallic iron and water. The metallic iron itself is a secondary mineral that forms as divalent (ferrous) iron is

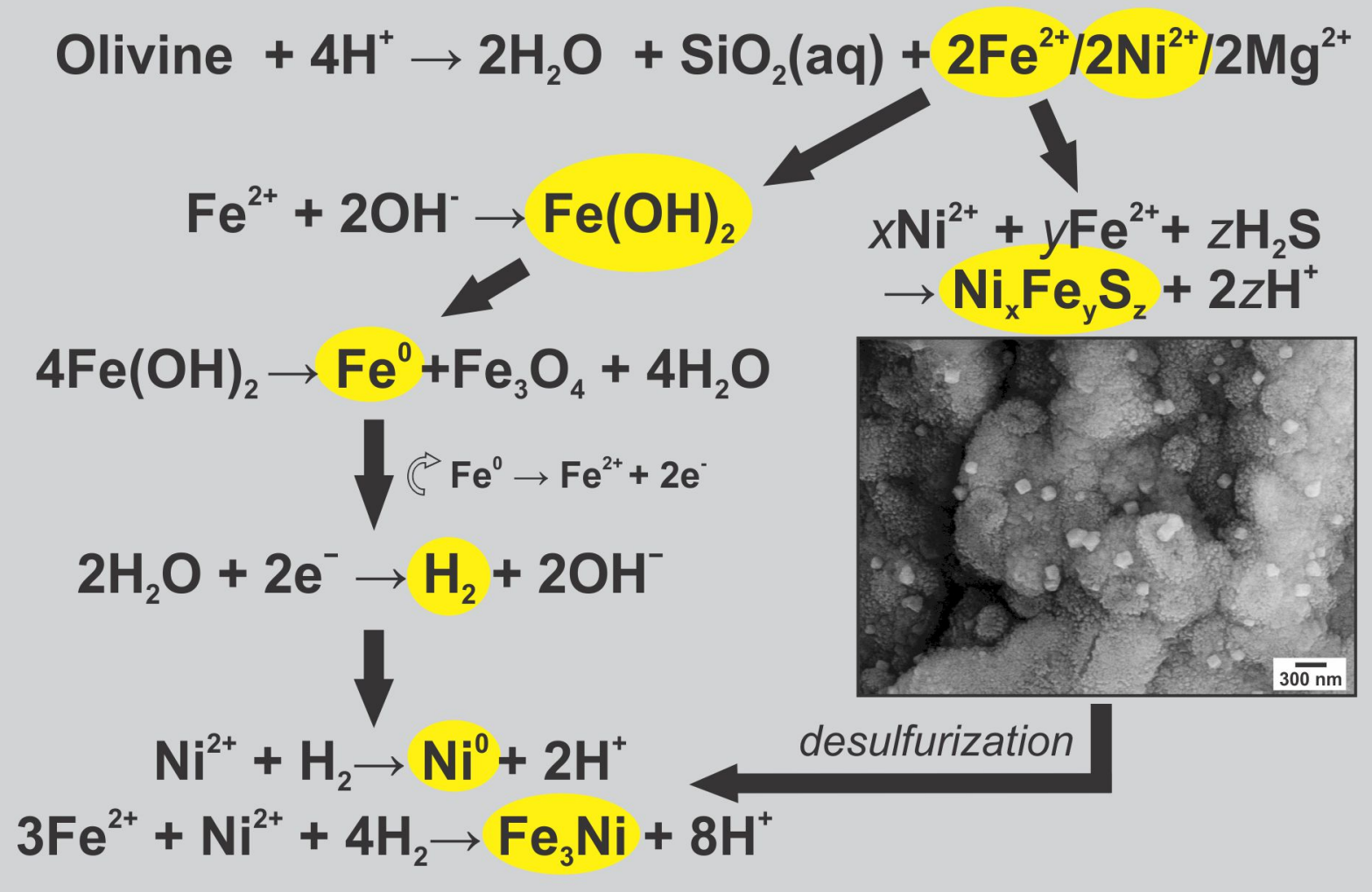

Figure 5. Schematic diagram illustrating the plausible formation of native nickel and nickel-iron alloys as a result of the reaction of olivine with water, based on earlier work by (Schrauzer and Guth 1976; Janecky and Seyfried 1986). The yellow ellipses highlight the fate of the metals involved and the formation of molecular hydrogen. Molecular hydrogen under these conditions reacts with inorganic carbon and nitrogen (Schrenk et al. 2013). The presence of the Ni-Fe alloys, such as awaruite, catalyze these processes. The inset is a scanning electron microscopy image of olivine (large dull crystals covered with a crust secondary Fe minerals) with small, 50 to $100 \mathrm{~nm} \mathrm{Ni-Fe-S} \mathrm{phases} \mathrm{(bright} \mathrm{phases)} \mathrm{formed} \mathrm{during} \mathrm{serpentinization} \mathrm{in} \mathrm{the}$ presence of $\mathrm{H}_{2} \mathrm{~S}$ (Smirnov unpublished experimental study). 
released from olivines. The release of heat increases the buoyancy of the resulting solution and triggers an upward movement. The buoyancy can drive solutions out of the rock into the overlying waters and establish a circulation pattern independent of tectonic setting. Any nickel contained in the olivine is essentially caught up in this serpentinization process and forms native nickel metal or nickel-iron alloys. The formation of metallic $\mathrm{Ni}\left(\mathrm{Ni}^{0}\right)$ and Ni.Fe alloys, especially awaruite $\left(\mathrm{Ni}_{3} \mathrm{Fe}\right.$ to $\left.\mathrm{Ni}_{2} \mathrm{Fe}\right)$ has been well documented in natural (modern and ancient) and experimentally simulated serpentinization systems (Filippidis 1985; Mevel 2003). Olivine is not unique as mineral-based hydrogen production has been documented for a number of ferrous-iron-containing minerals, including spinel (Mayhew et al. 2013). In the context of staging life, metallic nickel and iron, as well as their alloys are of particular interest because they facilitate the reduction and hydrogenation reactions of both $\mathrm{CO}_{2}$ and $\mathrm{N}_{2}$ (Horita and Berndt 1999; Smirnov et al. 2008).

The fate of nickel contained in olivine is further influenced by the availability of hydrogen sulfide. In a system free of hydrogen sulfide, $\mathrm{Ni}^{0}$ and awaruite are stable in the alkaline to mildly acidic $\mathrm{pH}$ range even at temperatures as high as $100^{\circ} \mathrm{C}$. In the presence of hydrogen sulfide, nickel-iron alloys are only stable at alkaline $\mathrm{pH}$ and they are replaced by sulfides of varying Ni:Fe:S ratios at low $\mathrm{pH}$. While the presence of sulfur decreases abundances of pure $\mathrm{Fe}-\mathrm{Ni}$ alloys/metals, sulfides such as heazlewoodite $\left(\mathrm{Ni}_{3} \mathrm{~S}_{2}\right)$, pentlandite $\left([\mathrm{Fe}, \mathrm{Ni}]_{9} \mathrm{~S}_{8}\right)$, pyrite $\left(\mathrm{FeS}_{2}\right)$ or mackinawite $(\mathrm{FeS})$ can also facilitate the formation of prebiotically useful reduced carbon and nitrogen compounds (Brandes et al. 1998; Schoonen and Xu 2001; Cody et al. 2004; Singireddy et al. 2012; Gordon et al. 2013).

Minerals can participate in reduction reactions mentioned above in one of two ways: as catalysts or as reactants (Schoonen et al. 1998). A catalyst, by definition, only facilitates reactions without net decrease in mass or reactive surface area. Therefore, even accessory amounts of $\mathrm{Ni}$-Fe metals and alloys, considered negligible on a planetary scale, could have provided globally important amounts of reaction products such as ammonia and reduced carbon compounds (Smirnov et al. 2008). Conversely, if $\mathrm{Ni}-\mathrm{Fe}$ metals and alloys participated as reactants, the yields of prebiotically useful products would be proportional to their spatial and temporal availability, and therefore strongly correlated with the rates of their formation (e.g., via serpentinization) and destruction (e.g., consumed in reactions). While it is challenging to address which of these modes would have been more prevalent on the Early Earth due to the complexity and local variability in conditions, both mechanisms have potential for introducing locally and even globally significant concentrations of prebiotically relevant compounds.

Overall the seltzer ocean stage of Early Earth may have been short but important in setting the stage for the origin of life aided by a combination of open and closed systems, each with their own suite of major and minor secondary minerals and fluids. During this stage the Earth may have been endowed with an assortment of organic molecules, primitive vesicles, and perhaps the first metabolic systems thriving on steep chemical gradients at the interfaces of open and closed systems. The reactions that drive the formation of secondary minerals in closed and mafic rock systems still operate today, but the amount of $\mathrm{CO}_{2}$ dissolved in the infiltrating solutions is significantly lower. Ironically, the closest analogs to the deep past are provided by attempts to curb the build up of atmospheric $\mathrm{CO}_{2}$ by injection of the greenhouse gas into basalts where some of it dissolves into water and reacts with the rock (Gysi and Stefánsson 2012; Tollefson 2013). 
Acknowledgements-NASA, through its Exobiology and Astrobiology program, provided more than a decade of funding to Schoonen's group at Stony Brook University to investigate the role of minerals, particularly sulfides, in shaping the conditions during the Hadean through theoretical and experimental approaches. Many students, including Alexander Smirnov, contributed to this effort. Collaborations, discussions, and student exchanges with Scott McLennan (Stony Brook University), Daniel Strongin (Temple University), John Peters (University of Montana), Hiroshi Ohmoto and Jim Kasting (Penn State), Tom McCollum (University of Colorado), George Cody (Carnegie), and Nita Sahai (Akron University) helped shape our work and thinking on this topic. Alexander Smirnov would like to thank Francis McCubbin (Johnson Space Center) for providing ongoing petrological perspective into his work. Schoonen is particularly thankful for the mentorship by $\mathrm{Hu}$ Barnes (Penn State) and the interaction with the late Dick Holland, who instilled an interest in the geochemistry of the early Earth. Jan Schoonen, Scott McLennan, two reviewers and editor are thanked for reviewing an earlier draft of the paper. Work on this paper was supported in part by the $R I S^{4} E$ node of the NASA Solar System Exploration Research Virtual Institute (SSERVI). This is SSERVI publication SERVI-2016-032. Brookhaven National Laboratory is supported by the Department of Energy-Office of Science.

\section{References}

Bethke, C. M. 2008, Geochemical and biogeochemical reaction modeling, New York, Cambridge University Press, 543 p.:

Brandes, J. A., Boctor, N. Z., Cody, G. D., Cooper, B. A., Hazen, R. M., and Yoder, H. S., Jr. 1998, Abiotic nitrogen reduction on the early Earth. Nature 395: 365-367.

Cleaves, H. J., Michalkova Scott, A., Hill, F. C., Leszczynski, J., Sahai, N., and Hazen, R. 2012, Mineral-organic interfacial processes: potential roles in the origins of life. Chemical Society Reviews 41: 5502-5525.

Cody, G. D., Boctor, N. Z., Brandes, J. A., Filley, T. R., Hazen, R. M., and Yoder, H. S. 2004, Assaying the catalytic potential of transition metal sulfides for abiotic carbon fixation. Geochimica et Cosmochimica Acta 68: 2185-2196.

Deamer, D. W., Dworkin, J. P., Sandford, S. A., Bernstein, M. P., and Allamandola, J. L. 2002, The first cell membranes. Astrobiology 2: 371-381.

Filippidis, A. 1985, Formation of Awaruite in the System Ni-Fe-Mg-Si-O-H-S and Olivine Hydration with $\mathrm{NaOH}$ Solution, an Experimental-Study. Economic Geology 80: 1974-1980.

Gordon, A. D., Smirnov, A., Shumlas, S. L., Singireddy, S., DeCesare, M., Schoonen, M. A. A., and Strongin, D. R. 2013, Reduction of Nitrite and Nitrate on Nano-dimensioned FeS. Origins of Life and Evolution of Biospheres 43: 305-322.

Gysi, A. P., and Stefánsson, A. 2012, Mineralogical aspects of CO2 sequestration during hydrothermal basalt alteration - An experimental study at 75 to $250{ }^{\circ} \mathrm{C}$ and elevated pC02. Chemical Geology 306-307: 146-159. 
Horita, J., and Berndt, M. E. 1999, Abiogenic methane formation and isotopic fractionation under hydrothermal conditions. Science 285: 1055-1057.

Janecky, D. R., and Seyfried, W. E. 1986, Hydrothermal Serpentinization of Peridotite within the Oceanic-Crust - Experimental Investigations of Mineralogy and Major Element Chemistry. Geochimica Et Cosmochimica Acta 50: 1357-1378.

Lyon, D. Y., Monier, J.-M., Dupraz, S., Freissinet, C., Simonet, P., and Vogel, T. M. 2010, Integrity and Biological Activity of DNA after UV Exposure. Astrobiology 10: 285292.

Mayhew, L. E., Ellison, E. T., McCollom, T. M., Trainor, T. P., and Templeton, A. S. 2013, Hydrogen generation from low-temperature water-rock reactions. Nature Geoscience 6: 478-484.

McCollum, T. M. 2013, Laboratory Simulations of Abiotic Hydrocarbon Formation in Earth's Deep Subsurface, in R.M., H., Jones, A. P., and Baross, J., eds., Carbon in Earth, p. 467494.

Meunier, A., Petit, S., Cockell, C. S., El Albani, A., and Beaufort, D. 2010, The Fe-Rich Clay Microsystems in Basalt-Komatiite Lavas: Importance of Fe-Smectites for Pre-Biotic Molecule Catalysis During the Hadean Eon. Origins of Life and Evolution of Biospheres 40: 253-272.

Mevel, C. 2003, Serpentinization of abyssal peridotites at mid-ocean ridges. Comptes Rendus Geoscience 335: 825-852.

Monnard, P. A., Apel, C. L., Kanavarioti, A., and Deamer, D. W. 2002, Influence of ionic inorganic solutes on self-assembly and polymerization processes related to the early forms of life: implications for a prebiotic aqueous medium. Astrobiology 2: 139-152.

Nisbet, E. G., and Sleep, N. H. 2001, The habitat and nature of early life. Nature 409: 10831091.

Nutman, A. P. 2006, Antiquity of the oceans and continents. Elements 2: 223-227.

Pizzarello, and Shock, E. 2016, Get title from Editor. Elements this volume.

Russell, M. J., Hall, A. J., and Martin, W. 2010, Serpentinization as a source of energy at the origin of life. Geobiology 8: 355-371.

Schoonen, M., Smirnov, A., and Cohn, C. A. 2004, A perspective on the role of minerals in prebiotic synthesis. Ambio 33: 539-551.

Schoonen, M. A. A., and Xu, Y. 2001, Nitrogen reduction under hydrothermal vent conditions: implications for the prebiotic synthesis of $\mathrm{C}-\mathrm{H}-\mathrm{O}-\mathrm{N}$ compounds. Astrobiology 1: 133-140.

Schoonen, M. A. A., Xu, Y., and Strongin, D. R. 1998, An introduction to geocatalysis. Journal of Geochemical Exploration 62: 201-215.

Schrauzer, G. N., and Guth, T. D. 1976, Hydrogen evolving systems .1. Formation of $\mathrm{H}_{2}$ from aqueous suspensions of $\mathrm{Fe}(\mathrm{OH})_{2}$ and reactions with reducible substrates, including molecular nitrogen. Journal of the American Chemical Society 98: 3508-3513.

Schrenk, M., Brazelton, W., and Lang, S. Q. 2013, Serpentinization, carbon and deep life, in R.M., H., Jones, A. P., and Baross, J., eds., Carbon in Earth: Washington, American Mineralogical Society, p. 575-606.

Singireddy, S., Gordon, A. D., Smirnov, A., Vance, M. A., Schoonen, M. A. A., Szilagyi, R. K., and Strongin, D. R. 2012, Reduction of Nitrite and Nitrate to Ammonium on Pyrite. Origins of Life and Evolution of Biospheres 42: 275-294. 
Sleep, N. H., Zahnle, K., and Neuhoff, P. S. 2001, Initiation of clement surface conditions on the earliest Earth. Proc Natl Acad Sci U S A 98: 3666-3672.

Smirnov, A., Hausner, D., Laffers, R., Strongin, D. R., and Schoonen, M. A. A. 2008, Abiotic ammonium formation in the presence of Ni-Fe metals and alloys and its implications for the Hadean nitrogen cycle. Geochemical Transactions 9.

Taylor, S. R., and McLennan, S. M. 2009, Planetary Crusts: Their composition, Origin and Evolution, Cambridge University Press, Cambridge Planetary Science, 378 p.:

Tollefson, J. 2013, Pilot projects bury carbon dioxide in basalt. Nature 500: 18.

Valley, J. W. 2006, Early Earth. Elements 2: 201-204.

Zahnle, K. 2006, Earth's earliest atmosphere. Elements 2: 217-222.

Zahnle, K., Schaefer, L., and Fegley, B. 2010, Earth's earliest atmospheres. Cold Spring Harbor Perspectives in Biology 2:a004895. 